\title{
An Efficient Hybrid Technique for Noise Reduction in Optical Gyroscope Signals
}

\author{
Hesham M. AbdelZaher \\ Communication Department \\ Faculty of Electronic Engineering El- \\ Menoufia University \\ El-Menoufia, Egypt \\ Eng.hesham205@gmail.com \\ Osama A. Oraby
Electrical Engineering Department
Faculty of Engineering
Damiatta University
Damiatta, Egypt
drosama_oraby3@hotmail.com \\ El_Sayed M. El_Rabaie \\ Communication Department \\ Faculty of Electronic Engineering El- \\ Menoufia University \\ El-Menoufia, Egypt \\ srabie1@yahoo.com
}

\author{
Ibrahim M. El-Dokany \\ Communication Department \\ Faculty of Electronic Engineering El- \\ Menoufia University \\ El-Menoufia, Egypt \\ Dokany_2006@hotmail.com \\ Moawad I. Dessouky \\ Communication Department \\ Faculty of Electronic Engineering El- \\ Menoufia University \\ El-Menoufia, Egypt \\ dr_moawad@yahoo.com
}

Fathi. E. Abd-El-Samie

Communication Department

Faculty of Electronic Engineering El-

Menoufia University

El-Menoufia, Egypt

Fathi_sayed@yahoo.com

\author{
Sami A. El-Dolil \\ Communication Department \\ Faculty of Electronic Engineering El- \\ Menoufia University \\ El-Menoufia, Egypt \\ Msel_dolil@yahoo.com
}

\author{
Adel El-fishawy \\ Communication Department \\ Faculty of Electronic Engineering El- \\ Menoufia University \\ El-Menoufia, Egypt \\ aelfishawy@hotmail.com
}

\begin{abstract}
Gyroscopes are sensors that are used for motion measurement. They are generally used to measure rotation rate of moving equipment. There are different types of gyroscopes including mechanical, micro-electromechanical (MEMS) and optical gyroscopes. Gyroscope signal suffers from internal noise due to internal device operation and external noise of the environment. This paper presents a proposed hybrid technique that includes both Kalman filter and wavelet denoising. Results show the superiority of this proposed technique to the other filters. Arranging the filters in cascaded hybrid structure has an effect on the performance of the hybrid technique. Using Kalman filter as a first stage is better than using the wavelet as a first stage. For the comparison, two evaluation metrics are used: Signal-to-Noise Ratio (SNR) improvement and correlation coefficient.
\end{abstract}

Keywords-Gyroscope, DWT, Wavelet denoising, Kalman filter, noise reduction.

\section{INTRODUCTION (HEADING l)}

Gyroscope is a very essential component in most motion detection equipments. The basic idea of operation of the gyroscope is transforming the angular movement of an abject into an electrical signal [1]. Different types of gyroscopes exist such as mechanical, MEMS and optical. Mechanical gyroscope is a free wheel that takes a certain 3D space. This wheel works based on conservation of the angular momentum principle. An angle acquisition unit is used to pick the orientation angle. This type has been developed based on using MEMS through the utilization of the Coriolis Effect that transforms motion into an electrical signal based on the motion of a metal sphere connected to a group of springs [2]. The type of interest in this paper is the fiber optic gyroscope. It is composed of a source, detector, optical directional coupler and optical fiber coil. It is based on Sagnac effect [3]. Two beams are entered at the same time into the optical fiber coil in opposite directions. These two beams are extracted from an optical source in two equal-length paths: clockwise and counter clockwise. Any rotation of the coil is either clockwise or counter clockwise leading to difference in signal paths. A photo detector is used to interpret the received optical signal into an electrical signal. Phase comparison is performed between the original signal from the source and the received signal. Phase difference is interpreted after that as a signal, which is further processed. This phase signal which directly reflects the orientation measured may suffer from some uncertainty represented as noise [4]. It is feasible to use some signal processing and noise reduction techniques on this signal.

Fiber Optic Gyroscope (FOG) consists of fiber coil, detector, light source, phase modulator and coupler. Noise can be generated by these parts of the device leading to accuracy degradation of strap down inertial navigation system SINS [5-6], such as structural resonance and drift errors resulting from variation of stress in fiber coil, and then accumulation of errors occurs. These drifts are submerged in the noise due to weak Sagnac effect.

Fractal and white noise are the main noise in FOG [7], and some fractal noise may have deterministic relationship with environmental effect such as temperature. Accuracy is limited by external environment noise and internal noise, due to internal device operation [8]. 
$\mathrm{Yu}$ and Stubberud presented an extend Kalman filter (EKF) to incorporate MEMS sensors to increase the accuracy [9]. The first recommended technology of gyroscope was by Ploen and Bayard [10]. They presented a virtual system of gyroscope that has four combined sensors. To increase the accuracy of the micro-electromechanical system (MEMS) gyroscope, a Kalman filter is designed to combine measurement outputs from the sensors of a gyroscope array.

Digital signal processing is important to detect signal of Integrated Optic Gyroscope (IOG). The output of the IOG contains many types of noise that exist in a wide range of frequencies. The main noise types are shot noise, thermal noise and relative intensity noise which all have Gaussian distributions [11,12]. In the frequency domain, the noise frequency spectrum is overlapped to the signal frequency spectrum. The noise that exists outside the band of transmission can be filtered out by a normal filter, while the noise that is overlapped with the signal cannot be separated. So, to extract signal from noise, we can use band pass filter (BPF). When IOG is rotated, a square wave signal is detected from photodetector, which is uncorrelated with noise. It can be easily separated.

The accuracy of the gyroscope can be improved by removing the noise from the data. Characterization of gyroscope sensors is more helpful with long term error modeling to increase the accuracy of the sensor. Errors like quantization error, drift rate ramp error, and angle random walk error may appear [13].

Signals of the gyroscope that have errors can be cleaned by applying wavelet denoising [14-15]. Computing the decompositions of the wavelet of the noisy signal is the main idea to adjust the obtained coefficients of the wavelet transform for noise reduction. Replacing coefficients affected by noise by zero values or other suitable values helps in reconstructing the signal using these coefficients.

In this paper, we discuss types of gyroscopes, gyroscope sensors, gyroscope signal and noise and will improve the signal and reduce the noise using wavelet denoising with various wavelet transforms and various levels of wavelet decomposition. This wavelet denoising technique has a high impact on accuracy of the sensor. A hybrid technique based on Kalman filtering and wavelet denoising is introduced in the paper to enhance gyroscope signal quality..

\section{EASE OF USE}

This section presents the main types of gyroscope such as mechanical, optical and micro-electro-mechanical systems (MEMS).

This section presents the main types of gyroscope such as mechanical, optical and micro-electro-mechanical systems (MEMS).

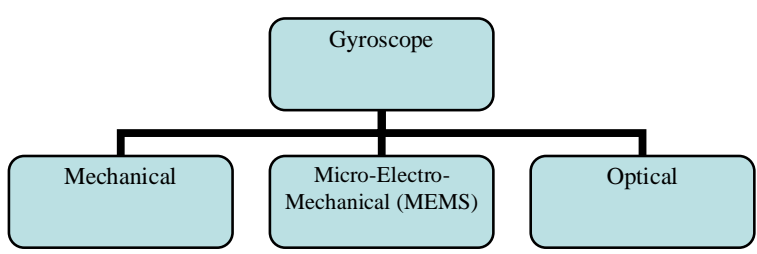

Fig. 1 Types of Gyroscopes

\section{A. Mechanical}

Mechanical gyroscope allows rotation in the 3D space due to containing a free wheel mounted on two gimbals. The free wheel works based on the conservation of angular momentum principles. Hence, during a mechanical gyroscope rotation, the orientation of the wheel stays regular with changing the angle between nearby gimbals [16]. An angle acquisition unit is used to pick the orientation angle. Existence of moving parts is a disadvantage for mechanical gyroscope, which causes drift of the output over time to friction.

\section{B. MEMS gyroscopes}

Micro-electro-mechanical system (MEMS) gyroscopes depend on the effect called Coriolis force. A MEMS gyroscope consists of a mass attached to a solid frame by springs. MEMS sensors are shown in Fig 1. They are constructed using silicon micro-machining techniques. MEMS gyroscopes usually have many advantages such as small size, low cost, low power consumption, high sensitivity, good linearity and high precision [17]. MEMS gyroscopes depend on parameters, where mass $\mathrm{m}$ is moving with velocity $\mathrm{v}$ and the angular velocity $\omega$.

$$
\mathrm{Fc}=-2 \mathrm{~m}(\omega \times \mathrm{v})
$$

\section{Coriolis Effect:}

Coriolis force effect transforms the sensor motion into electrical signal depending on the motion of the mass, which is connected to a group of springs $[18,19]$. The main idea of MEMS gyroscope depends on sensor vibration. Whenever external force of rotation occurs, new vibrations occur through the sensor [20]. We can define the Coriolis force as the physical quantity indicating inertia at work on a revolving coordinate system. 


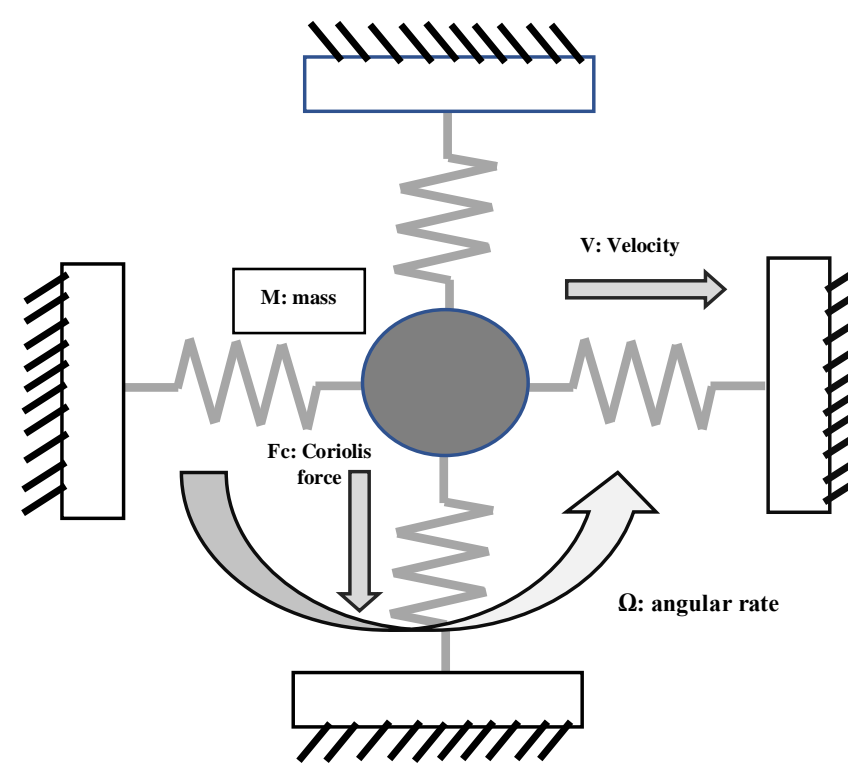

Fig. 2 MEMS Sensor

\section{Optical Gyroscopes}

The main type of optical gyroscopes is Fiber Optic Gyroscope (FOG). The angular velocity of FOG can be measured by light interference. A FOG contains a large coil of optical fiber that represents the path of the optical signal that exits the source of light. Then, a detector is used to detect the signal. For measuring the rotation, we have two beams entering to the fiber coil in opposite directions. If the sensor is rotating in the same direction of a beam of light source, the path will be longer for the light beam path than the other path, as illustrated in Figure 2. This process is called Sagnac effect [21]. Then, these beams, which exit the fiber coil are combined [22,4]. As a result of this combination, a phase shift depending on length difference path for these beams is produced. After combination of these beams, a beam is produced, which has a strength depending on the angular velocity [23]. The intensity of the combined beam should be measured to find the angular velocity. Figure 3 shows a sample of optical gyroscope.

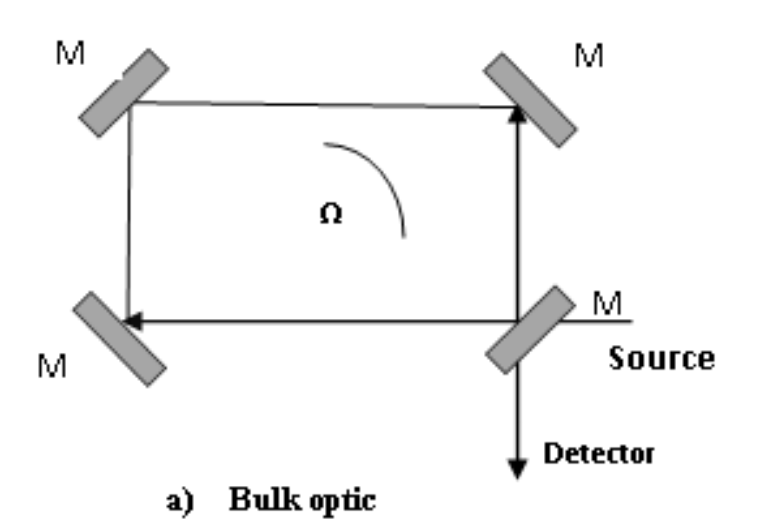

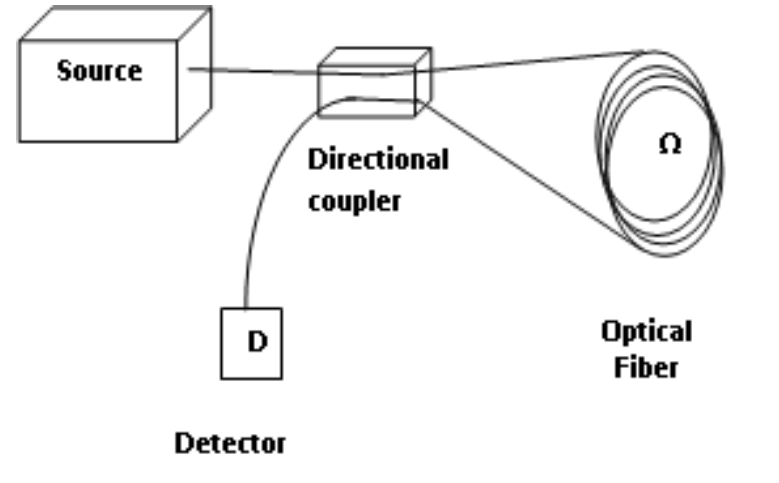

b) fiber optic

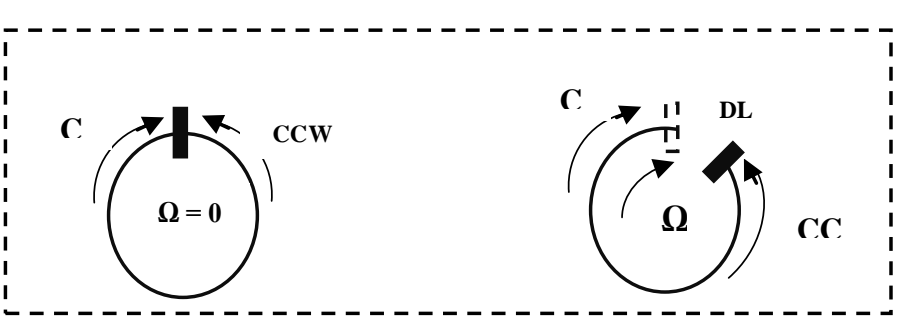

c) interferometer

Fig. 3 Optical gyroscopes

Optical Gyroscope Signal: -

We have two beams entering to the fiber coil in opposite directions as shown in Fig 4. If the coil is rotating in the same direction of a beam of light source, the path will be longer for the light beam path than the other path. This path difference enables to measure the rotation rate of the sensor.

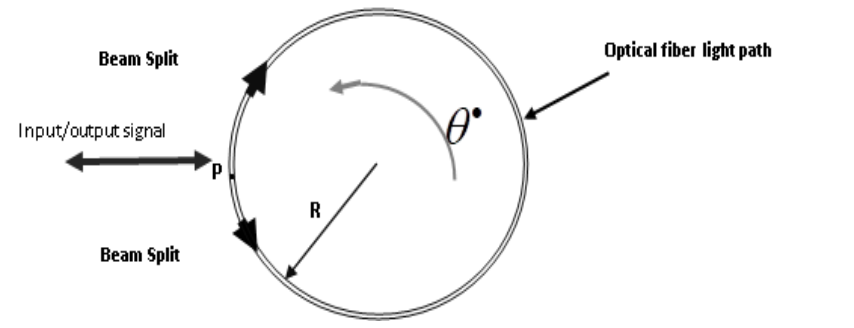

Figure 4. FOG Coil

For the first path, the distance will be:

$$
c t_{-}=2 \pi R-R \theta t_{-} \Rightarrow c t_{-}=\frac{2 \pi c R}{c+R \theta^{\square}}
$$

where $\mathrm{R}$ is the radius of the fiber coil, is the angular velocity and $\mathrm{c}$ is the speed of the light beam.

For the other path, the distance will be:

$$
c t_{+}=2 \pi R+R \theta t_{+} \Rightarrow c t_{+}=\frac{2 \pi c R}{c-R \theta^{\square}}
$$


The difference distance traveled by each signal is:

$$
\begin{aligned}
& d L=c\left(t_{+}-t_{-}\right)=2 \pi c R\left[\frac{1}{\left(c-R \theta^{\bullet}\right)}-\frac{1}{\left(c+R \theta^{\bullet}\right)}\right] \\
& d L=2 \pi c R\left[\frac{\left(c+R \theta^{\bullet}\right)}{\left(c^{2}-R^{2} \theta^{\cdot 2}\right)}-\frac{\left(c-R \theta^{\bullet}\right)}{\left(c+R^{2} \theta^{\cdot 2}\right)}\right]=2 \pi c R\left[\frac{2 R \theta^{\cdot}}{\left(c^{2}-R^{2} \theta^{\cdot 2}\right)}\right] \\
& c \gg R^{2} \theta^{\cdot 2}
\end{aligned}
$$

Path difference:

$$
d L=\frac{4 \pi R^{2} \theta^{\bullet}}{c}
$$

where $\mathrm{R}$ is the radius of the fiber coil, is the angular velocity and is the speed of the light beam.

Table 1 Types of Gyroscopes

\begin{tabular}{|c|c|c|c|}
\hline Type & Mechanical & MEMS & Optical \\
\hline Component & $\begin{array}{c}\text { Spin axis, } \\
\text { gimbal and rotor }\end{array}$ & $\begin{array}{c}\text { Springs and } \\
\text { mass }\end{array}$ & $\begin{array}{c}\text { Fiber coil, } \\
\text { detector, } \\
\text { coupler and } \\
\text { light source }\end{array}$ \\
\hline $\begin{array}{c}\text { Main idea } \\
\text { based on }\end{array}$ & $\begin{array}{c}\text { Mechanical parts } \\
\text { move to make } \\
\text { angles }\end{array}$ & Coriolis effect & Sagnac effect \\
\hline Advantages & $\begin{array}{c}\text { Simple, cheap } \\
\text { Simple, more } \\
\text { accurate }\end{array}$ & $\begin{array}{c}\text { Highest } \\
\text { accuracy, } \\
\text { small size }\end{array}$ \\
\hline Disadvantages & Bad accuracy & $\begin{array}{c}\text { Loss in } \\
\text { converting } \\
\text { motion to } \\
\text { electrical signal }\end{array}$ & Not simple \\
\hline
\end{tabular}

\section{TRADITIONAL TECHNIQUES FOR NOISE REDUCTION IN GYROSCOPE SIGNALS}

The main challenge of low-cost gyroscope signal is noise, bias and scaling factor, all of these challenges reduce accuracy of the sensor. So, the calibration for this type of gyroscopes is needed before implementation. Thus, linear encoders can be used to calibrate the sensor [24].

Keep your text and graphic files separate until after the text has been formatted and styled. Do not use hard tabs, and limit use of hard returns to only one return at the end of a paragraph. Do not add any kind of pagination anywhere in the paper. Do not number text heads-the template will do that for you.

\section{A. Kalman Filtering}

We have 4 parts in the system to improve the performance of this type of gyroscope, i.e. the encoder with DC motor to measure velocity and position, Kalman filtering to filter out the signal of the gyroscope and a part to compensate for errors by adaptive compensator as shown in Fig. 5.

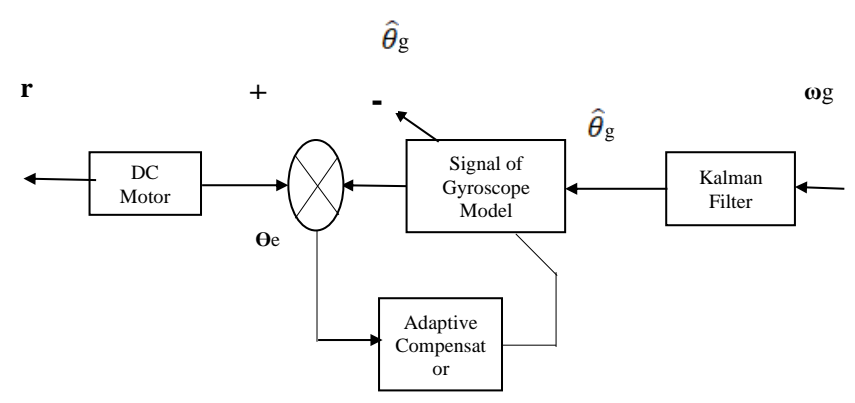

Fig. 5. Block diagram of signal conditioning

where $r$ is the reference input and $\theta_{e}$ is the angular displacement from encoder.

$$
\omega_{g}=\frac{1}{\alpha}(\hat{\theta}-\delta)+v_{g}
$$

where $\omega_{g}$ is the measured angular velocity and $\hat{\theta}$ is the actual angular velocity, $\alpha$ is a scaling factor and $\delta$ is bias factor, while $A=\pi r^{2}$, and the measurement noise of the gyroscope $v_{g}$. Then can get bias of the gyro by

$$
\hat{\delta}=v_{b}
$$

Where $v_{b}$ is Gaussian noise. State space model can be obtained at zero bias:

$$
\begin{gathered}
{\left[\begin{array}{l}
\hat{\hat{\delta}} \\
\hat{\omega_{g}}
\end{array}\right]=\left[\begin{array}{rr}
0 & 0 \\
-10
\end{array}\right]\left[\begin{array}{l}
\hat{\delta} \\
\hat{\theta_{g}}
\end{array}\right]+\left[\begin{array}{l}
M_{1} \\
M_{2}
\end{array}\right]\left[\begin{array}{l}
\theta_{g}-\hat{\theta}_{g}
\end{array}\right]} \\
z=\left[\begin{array}{ll}
0 & 1
\end{array}\right]\left[\begin{array}{l}
\delta \\
\theta_{g}
\end{array}\right]
\end{gathered}
$$

From Fig. 5, removing the noise by using Kalman filtering, we compensate for the errors by computing the parameters using nonlinear least squares method. We compare the encoder with the signal of the gyroscope [25].

$$
\dot{x}=\mathbf{E x}+\mathbf{F u}+\mathbf{G} \omega
$$




$$
\mathbf{z}=\mathbf{H x}+\mathbf{v}
$$

where $x$ is the state estimation of Kalman filtering, which is given by [9] :

$$
\hat{\mathbf{x}}=\mathbf{E} \hat{\mathbf{x}}+\mathbf{M}(\mathbf{z}-\mathbf{H} \hat{\mathbf{x}})
$$

where Kalman gain is,

$$
\mathbf{M}=\mathbf{P H}^{T} \mathbf{S}^{T}
$$

Then to get $\mathrm{P}$ from the below equation:

$$
\dot{\mathbf{P}}=\mathbf{E P}+\mathbf{P} \dot{\mathbf{E}}+\mathbf{G Q G}^{T}+\mathbf{M S M}^{T}
$$

The $\hat{\theta}_{g}$ denotes the signal from the Kalman filtering, $\omega$ is a process noise, $\mathbf{M}$ is the gain of the Kalman filter, $\mathbf{S}$ is the covariance matrix of the state estimation, $\mathbf{Q}$ is the covariance matrix , $\mathbf{G}$ is a covariance matrix of observation (measurement) and e is the error.

where $\mathbf{Q}=\left[\begin{array}{llll}5 & 0 ; & 0 & 5\end{array}\right]$ and $\mathbf{S}=1.1$, and $\mathbf{M}=[-2.1320 .2373]^{T}$

Then state space for Kalman Filter is:

$$
\left[\begin{array}{l}
\hat{\hat{\delta}} \\
\hat{\omega}_{g}
\end{array}\right]=\left[\begin{array}{cc}
0 & 0 \\
-1 & 0
\end{array}\right]\left[\begin{array}{l}
\hat{\delta} \\
\hat{\theta}_{g}
\end{array}\right]+\left[\begin{array}{l}
\mathbf{M}_{\mathbf{1}} \\
\mathbf{M}_{\mathbf{2}}
\end{array}\right]\left[\begin{array}{l}
\theta_{g}-\hat{\theta}_{g}
\end{array}\right]
$$

To get the least squares error (LSE)

$$
\begin{aligned}
& e=\theta_{e}-\hat{\theta}_{g} \\
& L S E=\sum_{i=1}^{n}\left(\theta_{e}\left(t_{i}\right)_{i}-\hat{\theta}_{g}\left(t_{i}\right)_{i}\right)^{2}
\end{aligned}
$$

From equation (11), we obtain

\section{Minimize}

$f(\alpha, \delta)=\sum_{i=1}^{n}\left(\theta_{e}\left(t_{i}\right)_{i}-\hat{\theta}_{g}\left(t_{i}\right)_{i}\right)^{2}$

where $\quad p=[\alpha \delta]^{T}$

$p_{k}=\left[\alpha_{k} \delta_{k}\right]$

where $k$ is circulation cycle and $n$ is the number of data samples of the signal that exits the Kalman filter.
The effects of $\mathbf{Q}$ is significant and it affects the overall performance of the filter. A basic way to think of $\mathbf{Q}$ is that it is a weighting factor. Considering a larger $\mathbf{Q}$ is equivalent to considering a larger uncertainty in the state equations, which is equivalent to trusting the result of these equations less, which effectively means that the filter should correct more with the measurement update.

\section{B. Wavelet Denoising}

An efficient technique to reduce noise is using wavelet denoising. Wavelet transform enables to accomplish frequency and time signal analysis [26]. We can get information with high resolution in the frequency and time domains using continuous wavelet transforms.

Wavelets have many sorts. Here, we will discuss two types: Haar and Daubechies wavelets [27]. We can consider that Haar wavelet is a particular case of the Daubechies wavelet.

The simplest wavelet type is the Haar wavelet. A discrete signal is resolved into two half-signals with the Haar transform. The first half signal is a working average or direction and the second half signal is a working difference or variation..

$$
P_{t}(\mathrm{U})=1+U \quad \text { and } \quad U=\frac{1}{2}\left(*^{-1}\right) \text {. }
$$

$$
P(z)=\frac{1}{2}\left(z+2+z^{-1}\right)=\frac{1}{2}(z+1)\left(1+z^{-1}\right)=G_{0}(z) H_{0}(z)
$$

Then

$$
\begin{aligned}
& H_{0}(z)=\frac{1}{2}\left(1+z^{-1}\right) \\
& G_{0}(z)=(z+1)
\end{aligned}
$$

Using these equations:

$$
H_{1}(z)=z^{-k} G_{0}(-z) \text { and } G_{1}(z)=z^{k} H_{0}(-z)
$$

with $k=1$, we get:

$$
G_{1}(z)=z H_{0}(-z)=\frac{1}{2} z\left(1-z^{-1}\right)=\frac{1}{2}(z-1)
$$

Equations (25) and (27) are not causal, but can be implemented if the whole signal is available.

$$
H_{1}(z)=z^{-1} G_{0}(-z)=z^{-1}(-z+1)=\left(z^{-1}-1\right)
$$




$$
P_{t}(Z)=(1+Z)^{2}(1+a Z)
$$

Going through the factorization process with $a=1 / 2$, we get:

$$
\begin{aligned}
& H_{0}(z)=\frac{1}{8}\left(-z^{2}+2 z+6+2 z^{-1}-z^{-2}\right) \\
& G_{0}(z)=\frac{1}{2}\left(z+2+z^{-1}\right)
\end{aligned}
$$

Using Eq 26 with $k=1$, we get:

$$
\begin{aligned}
& G_{1}(z)=z H_{0}(-z)=\frac{1}{8} z\left(-z^{2}-2 z+6-2 z^{-1}-z^{-2}\right) \\
& H_{1}(z)=z^{-1} G_{0}(-z)=\frac{1}{2} z^{-1}\left(-z+2-z^{-1}\right)
\end{aligned}
$$

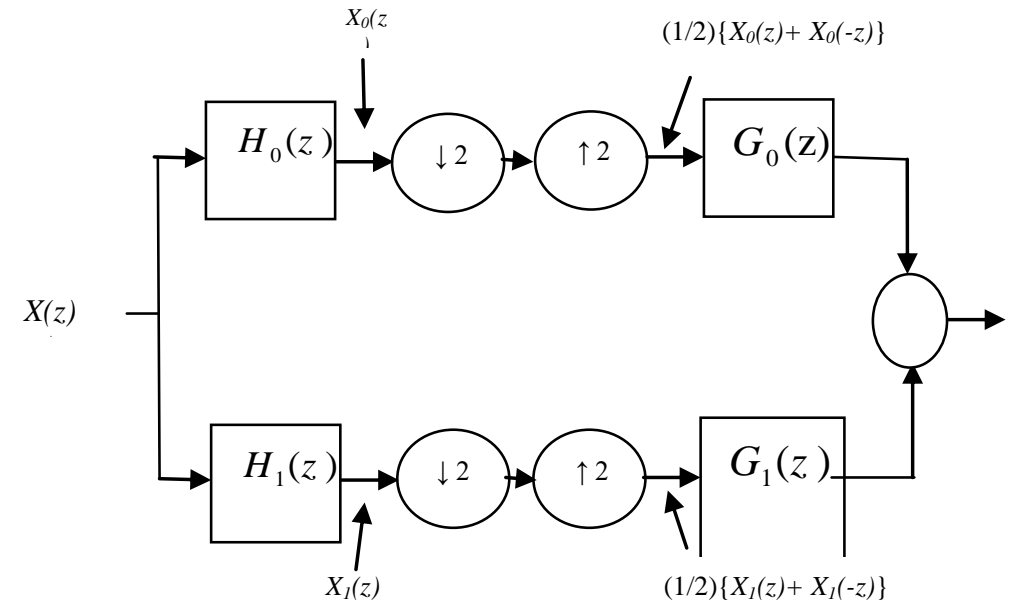

Fig 6. The two-band decomposition-reconstruction filter

$$
\text { bank }
$$

We choose a high threshold for denoising, which is sufficient for large variations of the noise in the signal. This threshold will remove most of the power of the noise. Right now, thresholding is composed of two types. The first thresholding type is hard thresholding and the second thresholding type is soft thresholding. We use rigrsure thresholding technique, which is based on Stein's unbiased estimate of risk (quadratic loss function). We can get an estimate of the risk for a particular threshold value $t$. Minimizing the risks in $t$ gives a selection of the threshold value [28]

For the first thresholding type which is hard:

$$
f_{\text {hard }}(x)= \begin{cases}x & |x| \geq T H \\ 0 & |x|<T H\end{cases}
$$

For the first thresholding type which is soft:

$$
f_{\text {soff }}(x)=\left\{\begin{array}{cc}
x & |x| \geq T H \\
2 x-T H & T H / 2 \leq x<T H \\
T H+2 x & -T H<x \leq-T H / 2 \\
0 & |x|<T H / 2
\end{array}\right.
$$

$x$ is the coefficients of the high frequency components and $\mathrm{TH}$ indicates the value of the threshold.

\section{The Proposed Hybrid TeChNIQUE FOR NOISE REDUCTION}

The proposed technique to reduce the gyroscope noise is to merge wavelet denoising with Kalman filtering. Wavelet denoising is shown in fig. 5. The wavelet transform performs correlation analysis. Therefore, the output is expected to be maximal, when the input signal most resembles the mother wavelet.

We suggest the utilization of several parallel structures for more noise reduction as illustrated in Figs (7.a) to (8.b). These structures are investigated and compared in performance.

Different realizations of the hybrid approaches are considered. In the first one, both Haar wavelet denoising and Kalman filtering are implemented in parallel and the results are averaged.

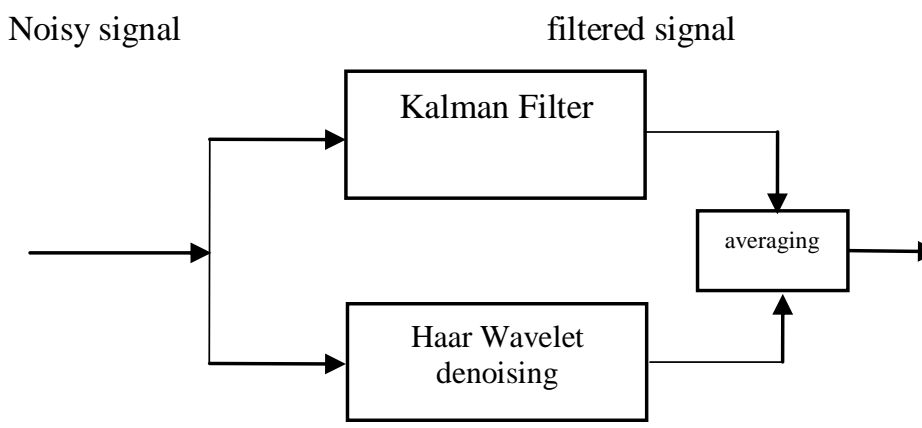

Fig (7.a) Parallel Hybrid structure of Kalman filtering and Haar wavelet denoising

In the second one, both Haar wavelet denoising and Daubechies wavelet denoising are implemented in parallel and the results are averaged.

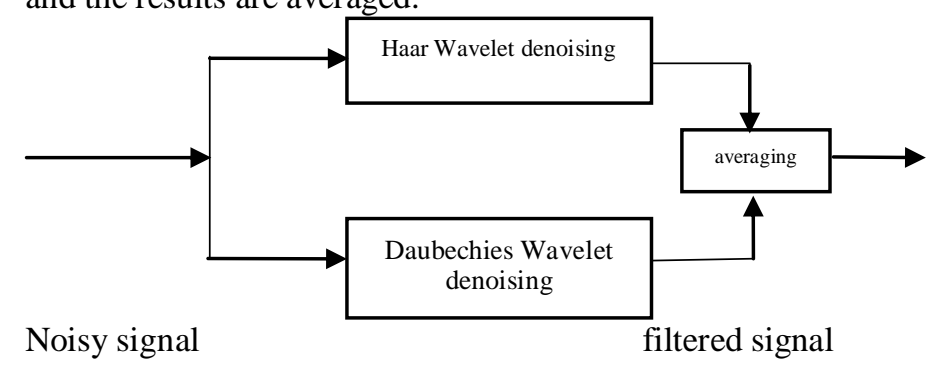

Fig (7.b) Parallel hybrid structure of Daubechies wavelet denoising and Haar wavelet denoising 
In the third one, both Haar wavelet denoising and Kalman filtering are implemented in cascaded mode, where the output of the Kalman filtering is the input of Haar wavelet denoising.

Noisy signal

filtered signal

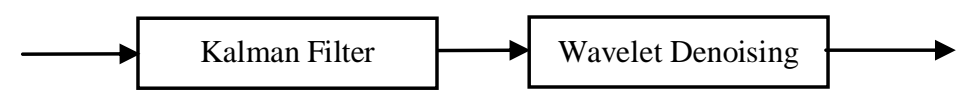

Fig (8.a) Cascaded hybrid structure of Kalman filtering and Haar wavelet denoising

In the fourth one, both Haar wavelet denoising and Kalman filtering are implemented in cascaded mode, where the output of the Haar wavelet denoising is the input of the Kalman filtering.

noisy signal

filtered signal

Wavelet Denoising

Kalman Filter

Fig (8.b) Cascaded hybrid structure of Haar wavelet denoising and Kalman filtering

\section{RESUlts}

Table 2 shows the parameters of Kalman filtering and wavelet denoising used in the simulation experiments.

Table 2 Dataset specifications [25,26,28]

\begin{tabular}{|c|l|}
\hline Parameter & \multicolumn{1}{|c|}{ Definition } \\
\hline Q & $\begin{array}{l}\text { Process noise parameter of } \\
\text { Kalman filter }(0.01,0.9)\end{array}$ \\
\hline Decomposition Level & $\begin{array}{l}3 \text { and 7 levels of wavelet } \\
\text { stages }\end{array}$ \\
\hline I/P SNR & Input signal to noise ratio \\
\hline O/P SNR & Output signal to noise ratio \\
\hline SNR Improvement & (O/P SNR - I/P SNR) \\
\hline Correlation Coefficient & $\begin{array}{l}\text { Correlation between output } \\
\text { signal and the input signal }\end{array}$ \\
\hline Cor-Co-Eff) & $\begin{array}{l}\text { Output of gyroscope sensor is } \\
\text { (deg / sec) }\end{array}$ \\
\hline
\end{tabular}

The input signal is the output of Gyroscope sensor during the rotation of the sensor. The input signal is simulated as shown in Fig (9) [29]. The noisy gyroscope signals at input $\mathrm{SNR}=-20 \mathrm{~dB}$ is shown in Fig (10). The noisy gyroscope signals at input $\mathrm{SNR}=20 \mathrm{~dB}$ is shown in Fig (11).

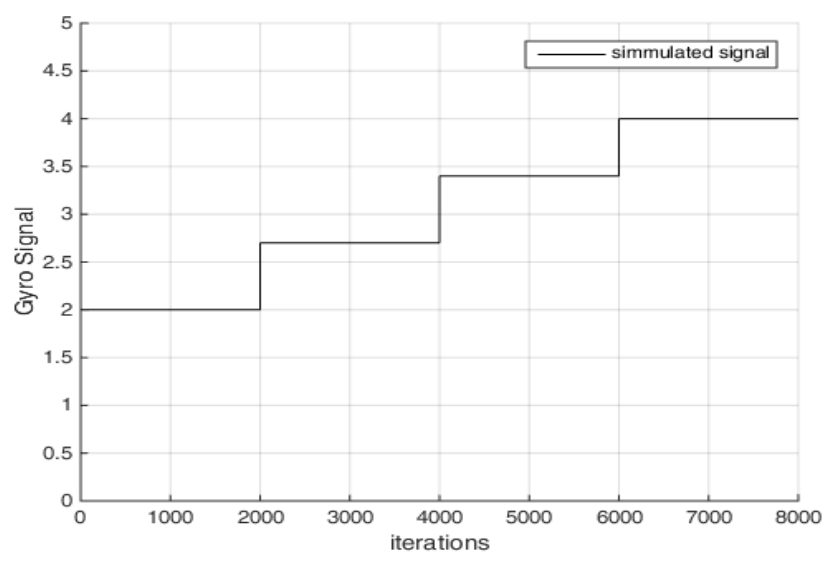

Fig 9. I/P Gyroscope signal

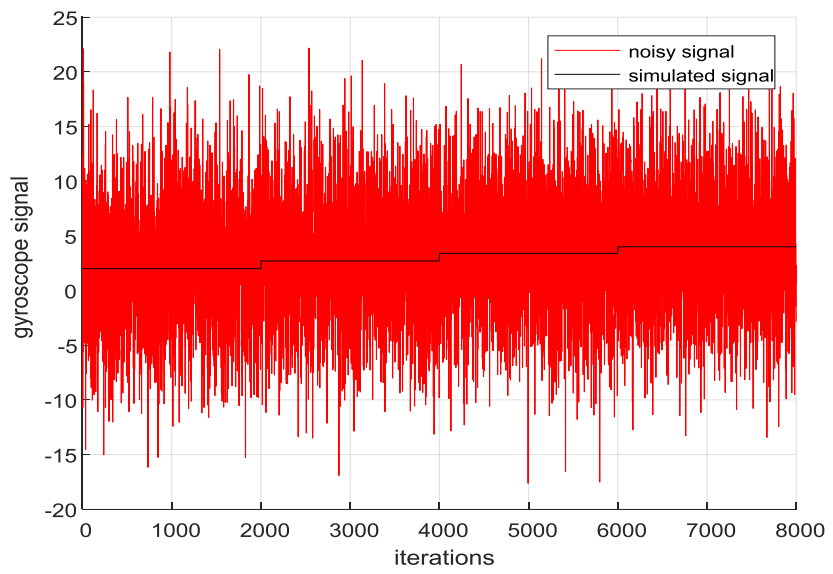

Fig (10) I/P Gyroscope signal at $\mathrm{SNR}=-20 \mathrm{~dB}$

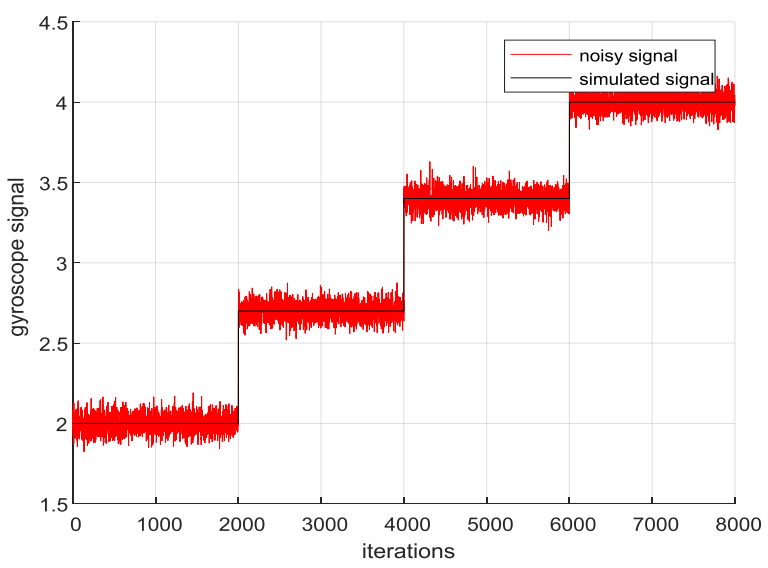

Fig (11) I/P Gyroscope signal at $\mathrm{SNR}=20 \mathrm{~dB}$

We have used Haar and Daubechies DB2 wavelet filters and Kalman filtering for denoising of the gyroscope signal at different SNRs. Different values of filter parameters are presented to show the effect of the chosen value on the performance. One of disadvantages of Kalman filtering is the longer processing time compared to wavelet denoising. 


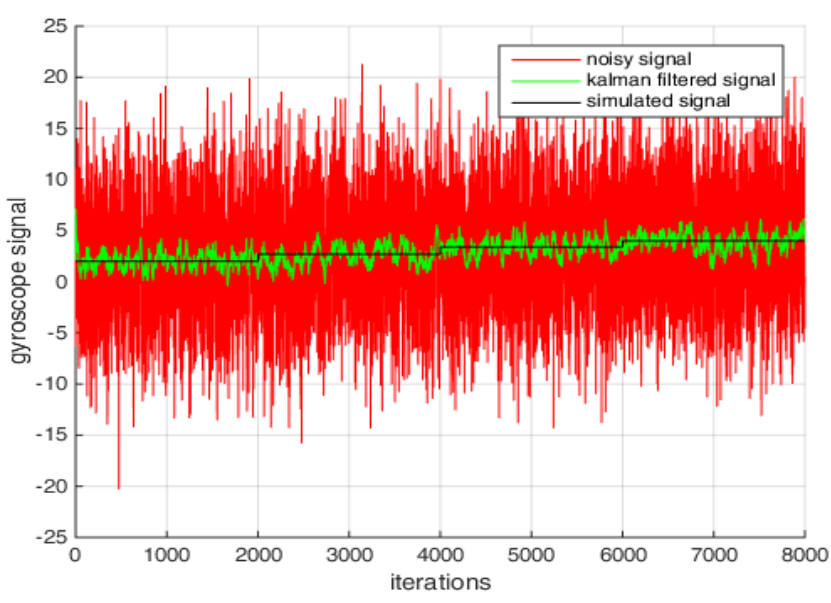

Fig 13. $\mathrm{O} / \mathrm{P}$ signal for Kalman filtering at $\mathrm{Q}=0.01$ when input $\mathrm{SNR}=-20 \mathrm{~dB}$

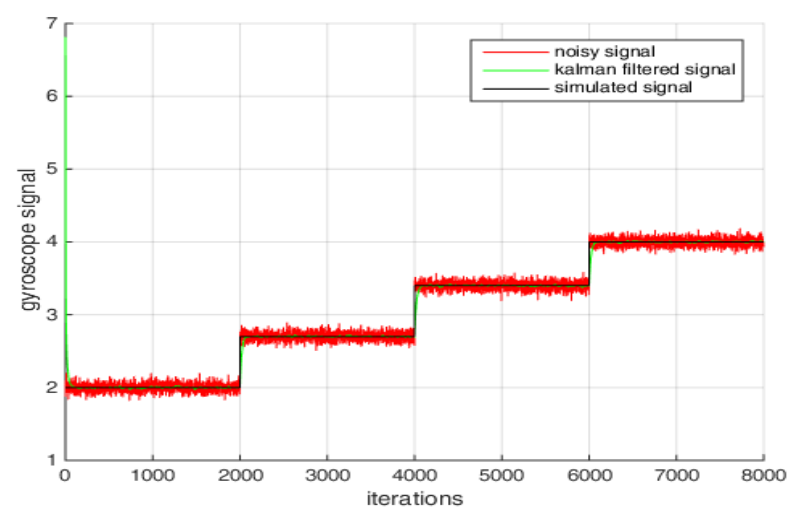

Fig 12. $\mathrm{O} / \mathrm{P}$ signal for Kalman filtering at $\mathrm{Q}=0.01$ when input $\mathrm{SNR}=20 \mathrm{~dB}$

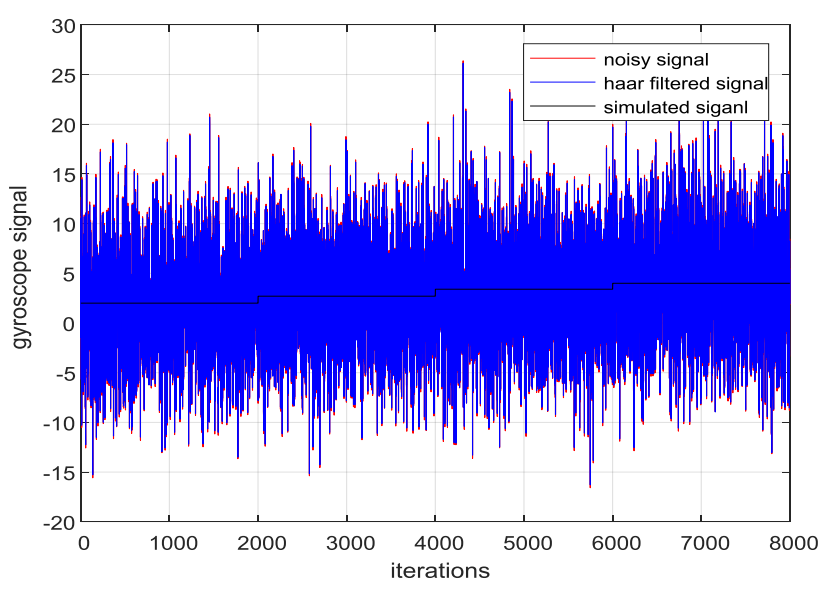

Fig 14.O/P signal for Haar wavelet at 7 levels of decomposition when input $\mathrm{SNR}=-20 \mathrm{~dB}$

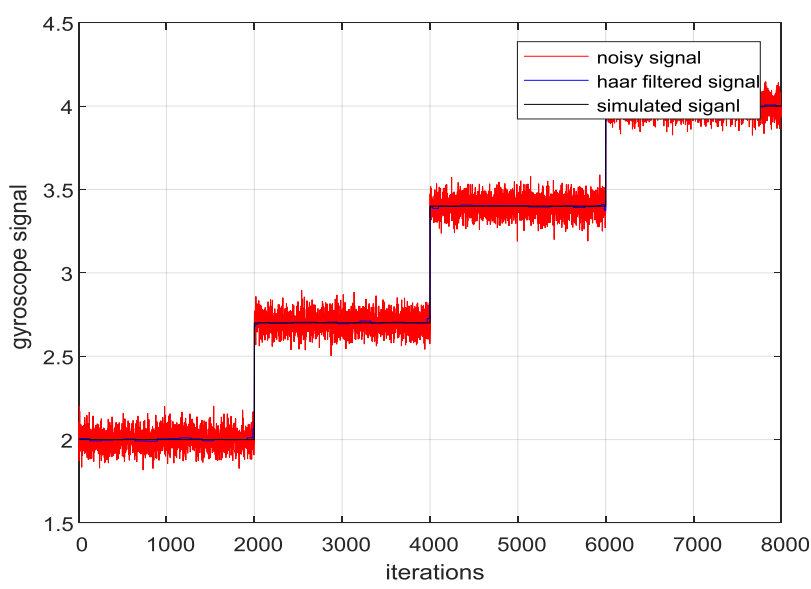

Fig 15. O/P signal for Haar wavelet at 7 levels of decomposition when input $\mathrm{SNR}=20 \mathrm{~dB}$

Table 3 Kalman filtering output metric values

\begin{tabular}{|c|c|c|c|c|c|}
\hline Filter & Parameters & $\begin{array}{c}\text { SNR } \\
\mathrm{I} / \mathrm{P}\end{array}$ & $\begin{array}{c}\text { SNR } \\
\mathrm{O} / \mathrm{P}\end{array}$ & $\begin{array}{c}\text { Improve } \\
\text {-ment }\end{array}$ & $\begin{array}{c}\text { Cor- } \\
\text { Co-eff }\end{array}$ \\
\hline \multirow{4}{*}{$\begin{array}{c}\text { Kalman } \\
\text { filter } \\
\text { Process noise } \\
\begin{array}{c}\text { Parameter } \\
\mathrm{Q}=\{.01,9\}\end{array}\end{array}$} & $\mathrm{Q}=0.9$ & -20 & 1.3796 & 21.3796 & 0.2563 \\
\cline { 2 - 6 } & $\mathrm{Q}=0.9$ & -10 & 11.3831 & 21.3831 & 0.6746 \\
\cline { 2 - 6 } & $\mathrm{Q}=0.9$ & 10 & 29.3575 & 19.3575 & 0.9901 \\
\cline { 2 - 6 } & $\mathrm{Q}=0.9$ & 20 & 33.5419 & 13.5419 & 0.9962 \\
\cline { 2 - 6 } & $\mathrm{Q}=0.01$ & -20 & 10.9018 & 30.9018 & 0.6238 \\
\cline { 2 - 6 } & $\mathrm{Q}=0.01$ & -10 & 20.3619 & 30.3619 & 0.9261 \\
\cline { 2 - 6 } & $\mathrm{Q}=0.01$ & 10 & 30.5736 & 20.5736 & 0.9924 \\
\cline { 2 - 6 } & $\mathrm{Q}=0.01$ & 20 & 30.8919 & 10.8919 & 0.9930 \\
\hline
\end{tabular}

Table 3 reveals that the best value in improvement is $30.9018 \mathrm{~dB}$ at input $\mathrm{SNR}=-20 \mathrm{~dB}$ and process noise $\mathrm{Q}=0.01$ and the best correlation coefficient is at input $\mathrm{SNR}=20 \mathrm{~dB}$ and process noise $\mathrm{Q}=0.01$
Table 4 Haar Wavelet filter output metric values

\begin{tabular}{|c|c|c|c|c|c|}
\hline Filter & $\begin{array}{c}\text { Param } \\
\text { eters }\end{array}$ & $\begin{array}{c}\text { SNR } \\
\text { I/P }\end{array}$ & SNR O/P & $\begin{array}{c}\text { Improve- } \\
\text { ment }\end{array}$ & $\begin{array}{c}\text { Cor- } \\
\text { Co-eff }\end{array}$ \\
\hline \multirow{4}{*}{$\begin{array}{c}\text { Haar } \\
\text { Wavelet }\end{array}$} & 7 Haar & -20 & -4.9623 & 15.0377 & 0.1409 \\
\cline { 2 - 6 } & 7 Haar & -10 & 7.3308 & 17.3308 & 0.4885 \\
\cline { 2 - 6 } $\begin{array}{c}\text { Decomposition } \\
\text { Levels (3,7) }\end{array}$ & 7Haar & 10 & 42.3129 & 32.3129 & 0.9995 \\
\cline { 2 - 6 } & 7Haar & 20 & 45.2884 & 25.2884 & 0.9997 \\
\cline { 2 - 6 } & 3Haar & -20 & -5.0597 & 14.9403 & 0.1331 \\
\cline { 2 - 6 } & 3Haar & -10 & 6.5016 & 16.5016 & 0.4408 \\
\cline { 2 - 6 } & 3Haar & 10 & 34.1191 & 24.1191 & 0.9967 \\
\cline { 2 - 6 } & 3Haar & 20 & 44.1147 & 24.1147 & 0.9996 \\
\hline
\end{tabular}

Table 4 reveals that the best value in improvement is $32.3129 \mathrm{~dB}$ at input $\mathrm{SNR}=10 \mathrm{~dB}$ and number of decomposition levels $=7$. The best correlation coefficient is at input $\mathrm{SNR}=20 \mathrm{~dB}$ and number of decomposition levels $=7$ due to the low noise level. 


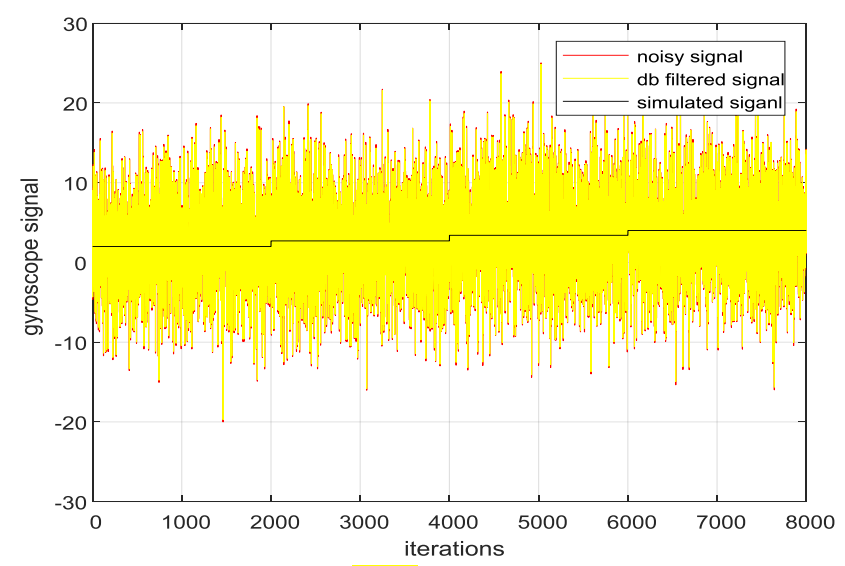

Fig 16. O/P signal for DB2 wavelet at 7 levels of decomposition when input $\mathrm{SNR}=-20 \mathrm{~dB}$

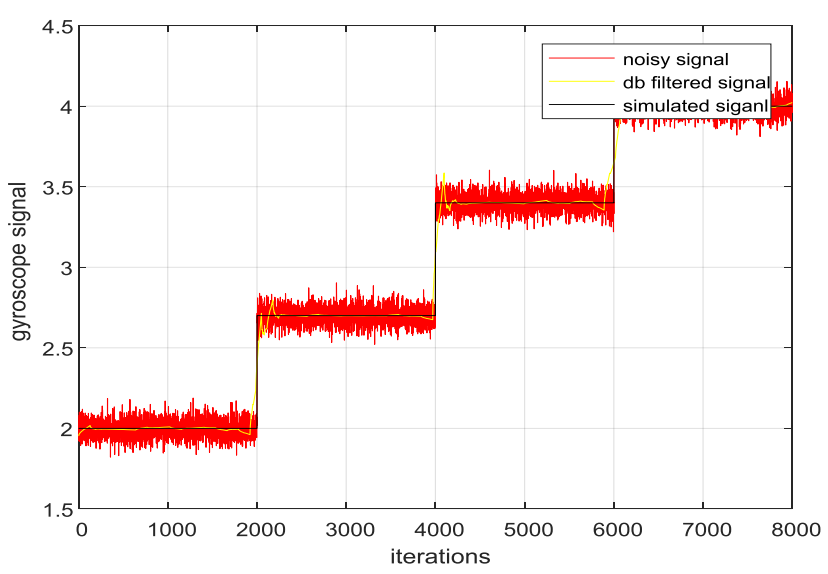

Fig 17. O/P signal for DB2 wavelet at 7 levels of decomposition when input $\mathrm{SNR}=20 \mathrm{~dB}$

Table 5 Daubechies wavelet filter output metric values

\begin{tabular}{|c|c|c|c|c|c|}
\hline Filter & Parameters & $\begin{array}{c}\text { SNR } \\
\text { I/P }\end{array}$ & $\begin{array}{c}\text { SNR } \\
\text { O/P }\end{array}$ & Improvement & $\begin{array}{c}\text { Cor- } \\
\text { Co-eff }\end{array}$ \\
\hline \multirow{4}{*}{$\begin{array}{c}\text { Daubichies } \\
\text { Wavelet } \\
\text { Decomposition } \\
\text { Levels (3,7) }\end{array}$} & 7DB2 & -20 & -4.8243 & 15.1757 & 0.1245 \\
\cline { 2 - 6 } & 7DB2 & -10 & 7.3865 & 17.3865 & 0.4865 \\
\cline { 2 - 6 } & 7DB2 & 10 & 37.4063 & 27.4063 & 0.9984 \\
\cline { 2 - 6 } & 7DB2 & 20 & 36.6649 & 16.6649 & 0.9981 \\
\cline { 2 - 6 } & 3DB2 & -20 & -4.8961 & 15.1039 & 0.1416 \\
\cline { 2 - 6 } & 3DB2 & -10 & 6.9405 & 16.9405 & 0.4739 \\
\cline { 2 - 6 } & 3DB2 & 20 & 43.6526 & 23.6526 & 0.9963 \\
\hline
\end{tabular}

Table 5 reveals that the best value in improvement is $27.4063 \mathrm{~dB}$ is at input $\mathrm{SNR}=10$ and number of decomposition levels $=7$. The best correlation coefficient is at input $\mathrm{SNR}=20 \mathrm{~dB}$ and number of decomposition levels $=3$ due to low noise level and more levels of decompositions leading to more noise.

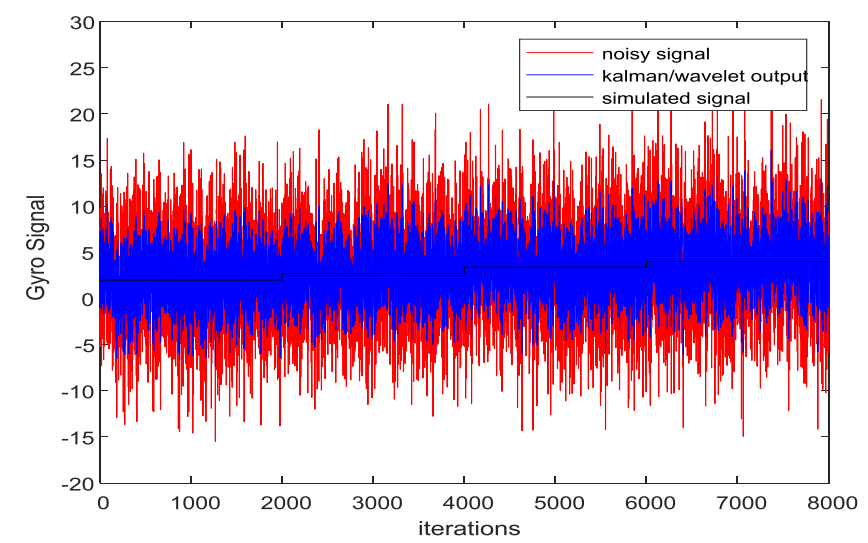

Fig 18. O/P signal for parallel mode Haar - Kalman at $\mathrm{Q}=0.01$ and 7 levels of decomposition when input $\mathrm{SNR}=-$ $20 \mathrm{~dB}$

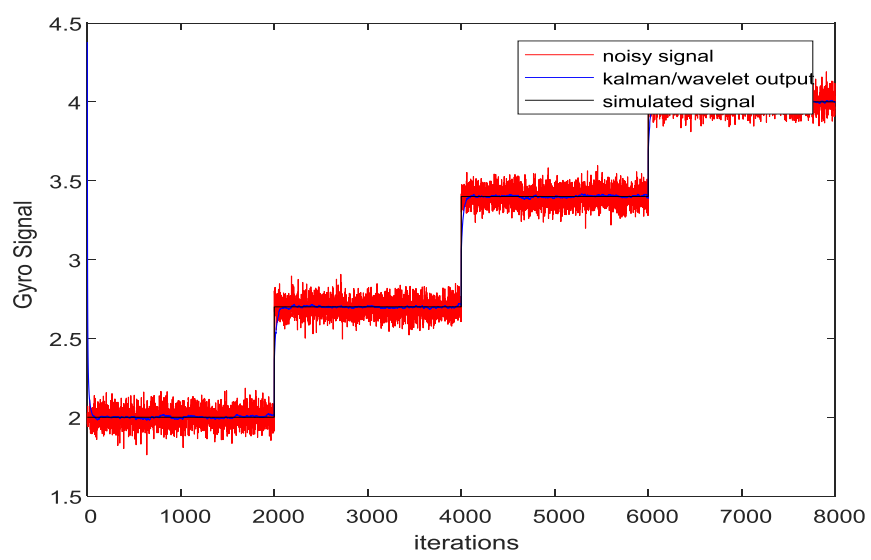

Fig 19. O/P signal for parallel mode Haar - Kalman at $\mathrm{Q}=0.01$ and 7 levels of decomposition when input $\mathrm{SNR}=20 \mathrm{~dB}$

Table 6 Parallel Mode Haar-Kalman output metric values

\begin{tabular}{|c|c|c|c|c|c|}
\hline Filters & Parameters & $\begin{array}{c}\text { SNR } \\
\mathrm{I} / \mathrm{P}\end{array}$ & $\begin{array}{c}\text { SNR } \\
\mathrm{O} / \mathrm{P}\end{array}$ & improvement & $\begin{array}{c}\text { Cor- } \\
\text { Co-eff }\end{array}$ \\
\hline \multirow{8}{*}{$\begin{array}{c}\text { Haar Wavelet } \\
\text { with } \\
\text { Daubechies } \\
\text { Wavelet } \\
\text { Decomposition } \\
\text { Levels } \\
(3,7)\end{array}$} & $\begin{array}{l}\text { 7Haar- } \\
\text { 7DB2 }\end{array}$ & -20 & -5.0490 & 14.951 & 0.1414 \\
\hline & $\begin{array}{l}\text { 7Haar- } \\
\text { 7DB2 }\end{array}$ & -10 & 7.2111 & 17.2111 & 0.4914 \\
\hline & $\begin{array}{l}\text { 7Haar- } \\
\text { 7DB2 }\end{array}$ & 10 & 39.7058 & 29.7058 & 0.9991 \\
\hline & $\begin{array}{l}\text { 7Haar- } \\
\text { 7DB2 }\end{array}$ & 20 & 42.0344 & 22.0344 & 0.9995 \\
\hline & $\begin{array}{l}\text { 3Haar- } \\
\text { 3DB2 }\end{array}$ & -20 & -4.9710 & 15.029 & 0.1368 \\
\hline & $\begin{array}{l}\text { 3Haar- } \\
\text { 3DB2 }\end{array}$ & -10 & 7.2745 & 17.2745 & 0.4931 \\
\hline & $\begin{array}{l}\text { 3Haar- } \\
\text { 3DB2 }\end{array}$ & 10 & 34.8872 & 24.8872 & 0.9972 \\
\hline & $\begin{array}{c}\text { 3Haar- } \\
\text { 3DB2 }\end{array}$ & 20 & 44.1575 & 24.1575 & 0.9997 \\
\hline
\end{tabular}


Table 6 reveals that the best value in improvement is $25.1555 \mathrm{~dB}$ is at input $\mathrm{SNR}=10 \mathrm{~dB}$ and process noise $\mathrm{Q}=0.01$ with number of decomposition levels $=7$. The best correlation coefficient is at input $\mathrm{SNR}=20$ and number of decomposition levels $=7$ and process noise $\mathrm{Q}=0.9$

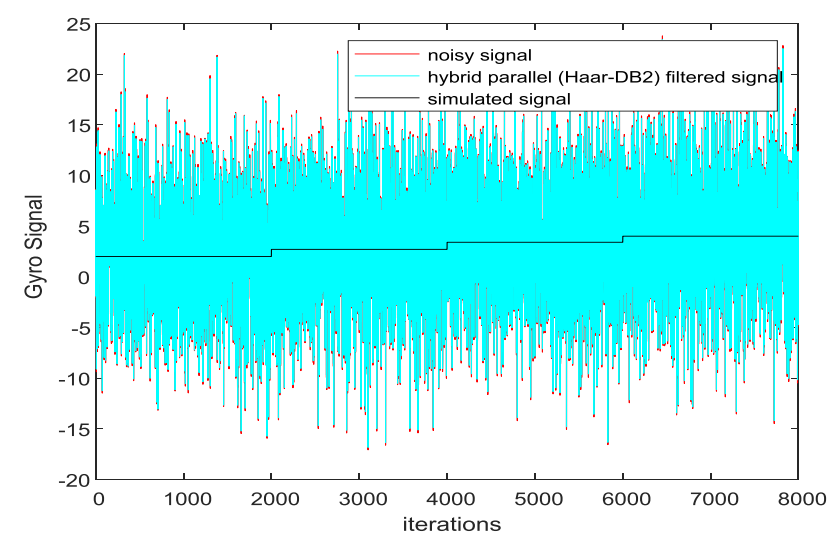

Fig 20. Filtered signal for parallel mode Haar - DB2 at 7 levels of decomposition when input $\mathrm{SNR}=-20 \mathrm{~dB}$

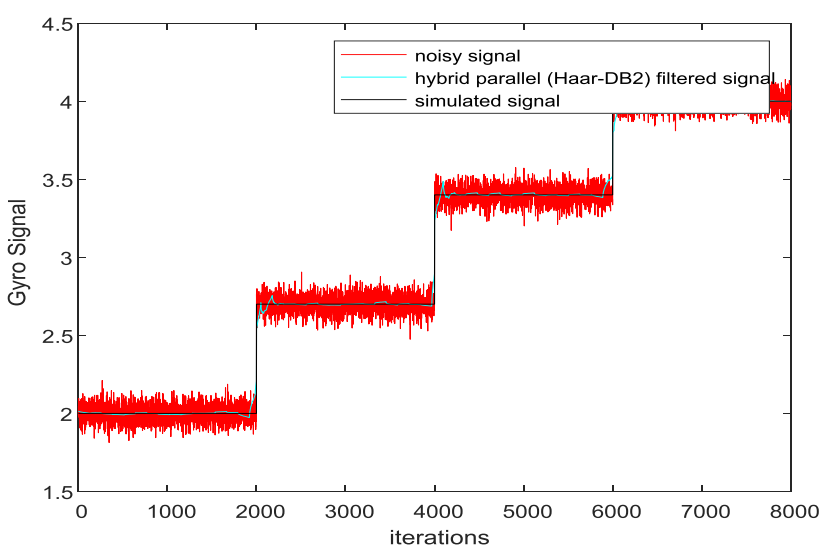

Fig 21. O/P signal for parallel mode Haar - DB2 at 7 levels of decomposition when input $\mathrm{SNR}=20 \mathrm{~dB}$

Table 7 reveals that the best value in improvement is $29.7058 \mathrm{~dB}$ is at input $\mathrm{SNR}=10$ and number of decomposition levels $=7$.
Table 7 Parallel Mode Haar-DB2 output metric values

\begin{tabular}{|c|c|c|c|c|c|}
\hline Filters & $\begin{array}{c}\text { Param } \\
\text { eters }\end{array}$ & $\begin{array}{c}\mathrm{SN} \\
\mathrm{R} \\
\mathrm{I} / \mathrm{P}\end{array}$ & $\begin{array}{l}\mathrm{SNR} \\
\mathrm{O} / \mathrm{P}\end{array}$ & $\begin{array}{c}\text { Improve- } \\
\text { ment }\end{array}$ & $\begin{array}{c}\text { Cor-Co- } \\
\text { eff }\end{array}$ \\
\hline \multirow{9}{*}{$\begin{array}{c}\text { Haar } \\
\text { Wavelet } \\
\text { with } \\
\text { Kalman } \\
\text { Decompos } \\
\text { ition } \\
\text { Levels( } 3,7 \\
\text { ) }\end{array}$} & $\begin{array}{c}\text { 7Haar } \\
- \\
\mathrm{Q}=0.9\end{array}$ & -20 & -1.8661 & 18.1339 & 0.1846 \\
\hline & $\begin{array}{c}\text { 7Haar } \\
- \\
\mathrm{Q}=0.9\end{array}$ & -10 & 9.2472 & 19.2472 & 0.5494 \\
\hline & $\begin{array}{c}\text { 7Haar } \\
- \\
\mathrm{Q}=0.9\end{array}$ & 10 & 34.6886 & 24.6886 & 0.9971 \\
\hline & $\begin{array}{c}\text { 7Haar } \\
- \\
\mathrm{Q}=0.9\end{array}$ & 20 & 39.3579 & 19.3579 & 0.9990 \\
\hline & $\begin{array}{c}\text { 7Haar } \\
- \\
\mathrm{Q}=0.0 \\
1\end{array}$ & -20 & 0.6070 & 20.607 & 0.2345 \\
\hline & $\begin{array}{c}\text { 7Haar } \\
- \\
\mathrm{Q}=0.0 \\
1\end{array}$ & -10 & 12.4743 & 22.4743 & 0.7178 \\
\hline & $\begin{array}{c}7 \text { Haar } \\
- \\
Q=0.0 \\
1\end{array}$ & 10 & 35.1555 & 25.1555 & 0.9974 \\
\hline & $\begin{array}{c}\text { 7Haar } \\
- \\
\mathrm{Q}=0.0 \\
1\end{array}$ & 20 & 36.9118 & 16.9118 & 0.9982 \\
\hline & $\begin{array}{c}3 \text { Haar } \\
- \\
\mathrm{Q}=0.9\end{array}$ & -20 & -1.9691 & 18.0309 & 0.1780 \\
\hline \multirow{7}{*}{$\begin{array}{c}\text { Process } \\
\text { noise } \\
\text { Parameter } \\
\mathrm{Q}=\{0.01 \\
, 0.9\}\end{array}$} & $\begin{array}{c}\text { 3Haar } \\
- \\
\mathrm{Q}=0.9\end{array}$ & -10 & 9.1210 & 19.121 & 0.5595 \\
\hline & $\begin{array}{c}3 \text { Haar } \\
- \\
Q=0.9\end{array}$ & 10 & 32.6872 & 22.6872 & 0.9954 \\
\hline & $\begin{array}{c}3 \text { Haar } \\
- \\
Q=0.9\end{array}$ & 20 & 38.5642 & 18.5642 & 0.9988 \\
\hline & $\begin{array}{c}3 \text { Haar } \\
- \\
\mathrm{Q}=0.0 \\
1\end{array}$ & -20 & 0.5089 & 20.5089 & 0.2560 \\
\hline & $\begin{array}{c}3 \text { Haar } \\
- \\
\mathrm{Q}=0.0 \\
1\end{array}$ & -10 & 12.2586 & 22.2586 & 0.7018 \\
\hline & $\begin{array}{c}3 \text { Haar } \\
- \\
Q=0.0 \\
1\end{array}$ & 10 & 34.3822 & 24.3822 & 0.9969 \\
\hline & $\begin{array}{c}3 \text { Haar } \\
- \\
Q=0.0 \\
1\end{array}$ & 20 & 36.6706 & 16.6706 & 0.9981 \\
\hline
\end{tabular}




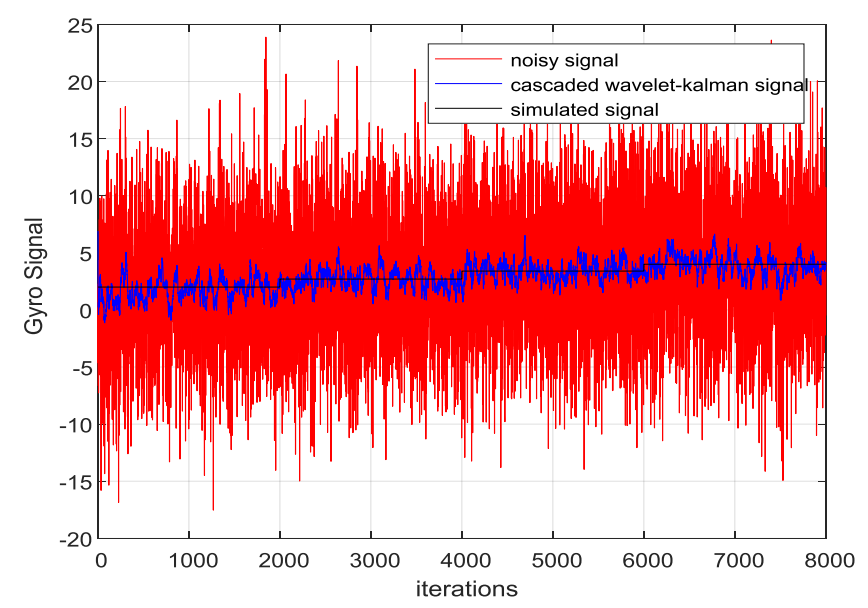

Fig 22. O/P signal for cascaded mode Haar - Kalman at $\mathrm{Q}=0.01$ and 7 levels of decomposition when input $\mathrm{SNR}=$ $20 \mathrm{~dB}$

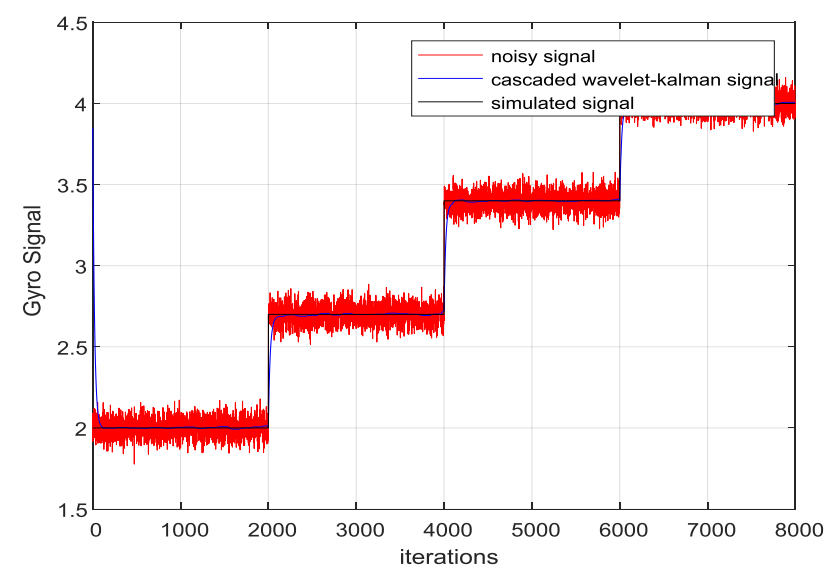

Fig 23. O/P signal for cascaded mode Haar - Kalman at $\mathrm{Q}=0.01$ and 7 levels of decomposition when input $\mathrm{SNR}=$ $20 \mathrm{~dB}$

Table 8 Cascaded Mode 7 levels Haar wavelet then Kalman output metric values

\begin{tabular}{|c|c|c|c|c|c|}
\hline Filters & Parameters & $\begin{array}{c}\mathrm{SNR} \\
\mathrm{I} / \mathrm{P}\end{array}$ & SNR O/P & improvement & $\begin{array}{l}\text { Cor-Co- } \\
\text { eff }\end{array}$ \\
\hline \multirow{4}{*}{$\begin{array}{c}\text { Kalman } \\
\text { then } \\
\text { wavelet }\end{array}$} & $\begin{array}{l}\mathrm{Q}=0.9- \\
7 \mathrm{Haar}\end{array}$ & -20 & 2.0638 & 22.0638 & 0.2967 \\
\hline & $\begin{array}{l}\mathrm{Q}=0.9- \\
7 \mathrm{Haar}\end{array}$ & -10 & 18.3946 & 28.3946 & 0.8879 \\
\hline & $\begin{array}{l}\mathrm{Q}=0.9- \\
7 \mathrm{Haar}\end{array}$ & 10 & 39.1728 & 29.1728 & 0.9990 \\
\hline & $\begin{array}{l}\mathrm{Q}=0.9- \\
7 \text { Haar }\end{array}$ & 20 & 42.0791 & 22.0791 & 0.9995 \\
\hline \multirow{4}{*}{$\begin{array}{l}\text { Q: process noise } \\
\text { parameter } \\
7 \text { Levels } \\
\text { decomposition }\end{array}$} & $\begin{array}{c}\mathrm{Q}=0.01- \\
\text { 7Haar }\end{array}$ & -20 & 12.5599 & 32.5599 & 0.6998 \\
\hline & $\begin{array}{c}\mathrm{Q}=0.01- \\
\text { 7Haar }\end{array}$ & -10 & 26.4251 & 36.4251 & 0.9819 \\
\hline & $\begin{array}{c}\mathrm{Q}=0.01- \\
7 \mathrm{Haar}\end{array}$ & 10 & 31.3047 & 21.3047 & 0.9936 \\
\hline & $\begin{array}{c}\mathrm{Q}=0.01- \\
\text { 7Haar }\end{array}$ & 20 & 32.0553 & 12.0553 & 0.9946 \\
\hline
\end{tabular}

Table 8 reveals that the best value in improvement is $31.977 \mathrm{~dB}$ is at input $\mathrm{SNR}=-10$ and process noise $\mathrm{Q}=0.01$ with number of decomposition levels $=7$ and the best correlation coefficient is at input $\mathrm{SNR}=20$ and number of decomposition levels=7 and process noise $\mathrm{Q}=0.9$

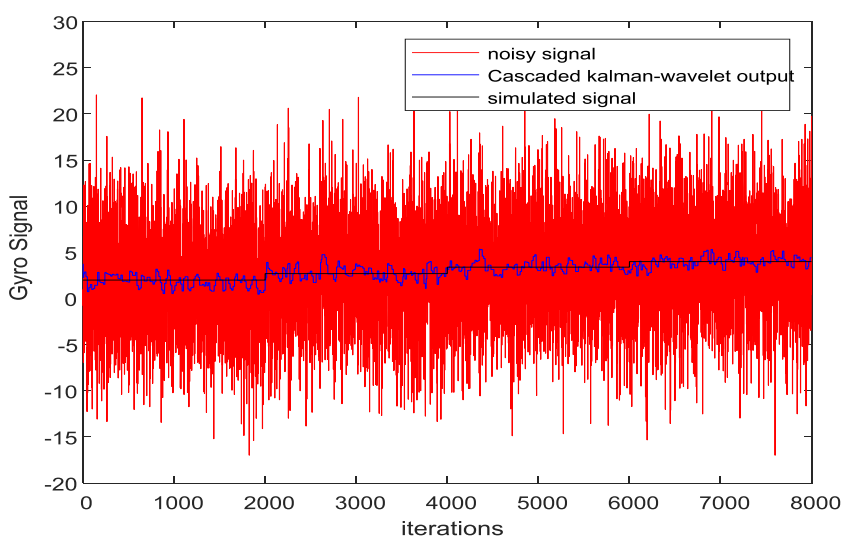

Fig 24. O/P signal for cascaded mode Kalman - Haar at $\mathrm{Q}=0.01$ and 7 levels of decomposition when input $\mathrm{SNR}=$ $20 \mathrm{~dB}$

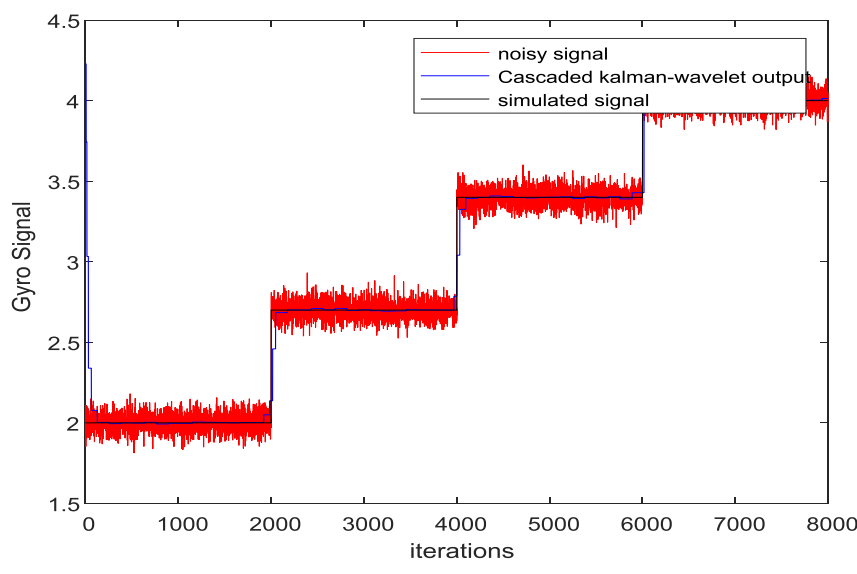

Fig 25. O/P signal for cascaded mode Kalman - Haar at $\mathrm{Q}=0.01$ and 7 levels of decomposition when input $\mathrm{SNR}=$ $20 \mathrm{~dB}$

Table 9 Cascaded Mode Kalman- 7 levels Haar wavelet output metric values

\begin{tabular}{|c|c|c|c|c|c|}
\hline Filters & $\begin{array}{c}\text { Paramete } \\
\text { rs }\end{array}$ & $\begin{array}{c}\text { SNR } \\
\mathrm{I} / \mathrm{P}\end{array}$ & $\begin{array}{l}\text { SNR } \\
\mathrm{O} / \mathrm{P}\end{array}$ & $\begin{array}{c}\text { Improve- } \\
\text { ment }\end{array}$ & $\begin{array}{l}\text { Cor-Co- } \\
\text { eff }\end{array}$ \\
\hline \multirow{3}{*}{$\begin{array}{c}\text { Wavelet } \\
\text { then } \\
\text { Kalman }\end{array}$} & $\begin{array}{l}\text { 7Haar- } \\
Q=0.9\end{array}$ & -20 & 1.3235 & 21.3235 & 0.2379 \\
\hline & $\begin{array}{l}\text { 7Haar- } \\
\mathrm{Q}=0.9\end{array}$ & -10 & 13.4628 & 23.4628 & 0.7451 \\
\hline & $\begin{array}{l}\text { 7Haar- } \\
\mathrm{Q}=0.9\end{array}$ & 10 & 38.2849 & 28.2849 & 0.9988 \\
\hline \multirow{5}{*}{$\begin{array}{c}\text { Q: process } \\
\text { noise } \\
\text { parameter } \\
7 \text { Levels } \\
\text { decompositio } \\
n\end{array}$} & $\begin{array}{l}\text { 7Haar- } \\
\mathrm{Q}=0.9\end{array}$ & 20 & 42.9948 & 22.9948 & 0.9996 \\
\hline & $\begin{array}{l}\text { 7Haar- } \\
\mathrm{Q}=0.01\end{array}$ & -20 & 10.9361 & 30.9361 & 0.6909 \\
\hline & $\begin{array}{l}\text { 7Haar- } \\
Q=0.01\end{array}$ & -10 & 21.9770 & 31.977 & 0.9489 \\
\hline & $\begin{array}{l}\text { 7Haar- } \\
\mathrm{Q}=0.01\end{array}$ & 10 & 31.6101 & 21.6101 & 0.9940 \\
\hline & $\begin{array}{l}\text { 7Haar- } \\
\mathrm{Q}=0.01\end{array}$ & 20 & 31.7651 & 11.7651 & 0.9942 \\
\hline
\end{tabular}

Table 9 reveals that the best value in improvement is $36.4251 \mathrm{~dB}$ at input $\mathrm{SNR}=-10$ and process noise $\mathrm{Q}=0.01$ with number of decomposition levels $=7$. The best correlation coefficient is at input $\mathrm{SNR}=20$ and number of decomposition levels $=7$ and process noise $\mathrm{Q}=0.9$ 


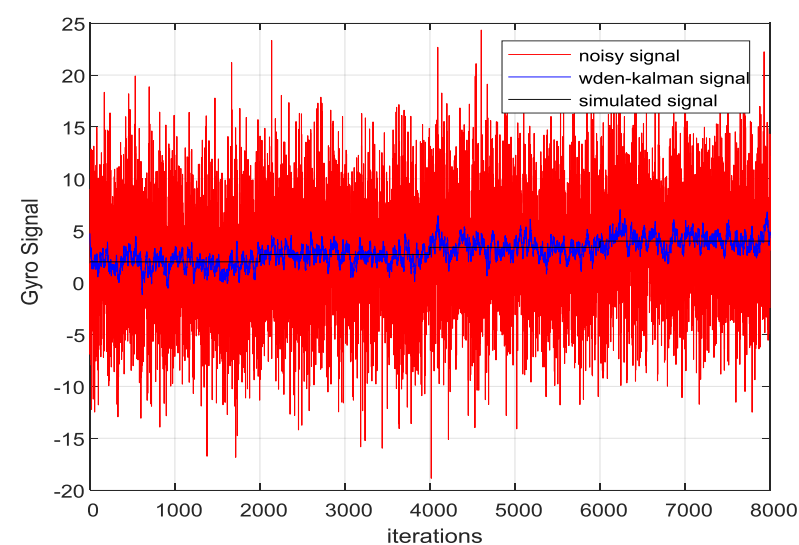

Fig 26. O/P signal for cascaded mode Haar - Kalman at $\mathrm{Q}=0.01$ and 3 levels of decomposition when input $\mathrm{SNR}=$ $20 \mathrm{~dB}$

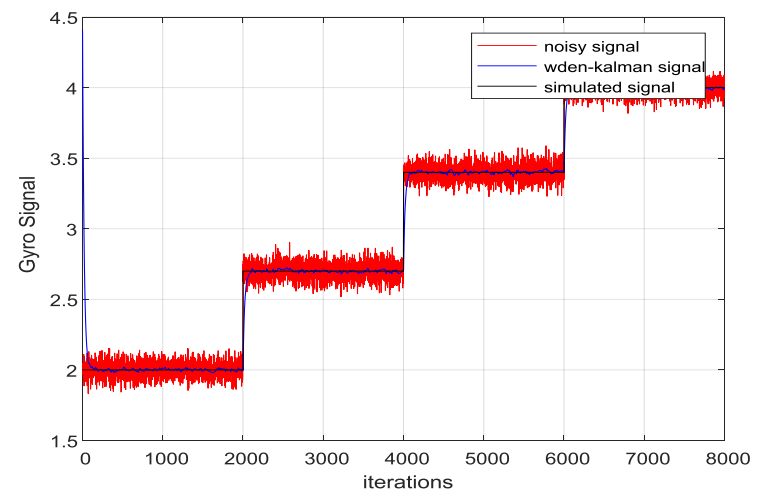

Fig 27. O/P signal for cascaded mode Haar - Kalman at $\mathrm{Q}=0.01$ and 3 levels of decomposition when input $\mathrm{SNR}=$ $20 \mathrm{~dB}$

Table 10 Cascaded Mode 3levels Haar wavelet then Kalman output metric values

\begin{tabular}{|c|c|c|c|c|c|}
\hline Filters & Parameters & $\begin{array}{c}\mathrm{SN} \\
\mathrm{R} \\
\mathrm{I} / \mathrm{P}\end{array}$ & $\begin{array}{l}\mathrm{SNR} \\
\mathrm{O} / \mathrm{P}\end{array}$ & $\begin{array}{c}\text { Improve } \\
\text {-ment }\end{array}$ & $\begin{array}{c}\text { Cor-Co- } \\
\text { eff }\end{array}$ \\
\hline \multirow{3}{*}{$\begin{array}{c}\text { Wavelet } \\
\text { then } \\
\text { Kalman }\end{array}$} & $\begin{array}{l}3 \text { Haar- } \\
Q=0.9\end{array}$ & -20 & 1.3252 & 21.3252 & 0.2598 \\
\hline & $\begin{array}{l}3 \text { Haar- } \\
\mathrm{Q}=0.9\end{array}$ & -10 & 12.3408 & 22.3408 & 0.7133 \\
\hline & $\begin{array}{l}3 \text { Haar- } \\
\mathrm{Q}=0.9\end{array}$ & 10 & 34.5778 & 24.5778 & 0.9970 \\
\hline \multirow{5}{*}{$\begin{array}{l}\text { Q: process } \\
\text { noise } \\
\text { parameter } \\
3 \text { Levels } \\
\text { decomposit } \\
\text { ion }\end{array}$} & $\begin{array}{l}3 \text { Haar- } \\
\mathrm{Q}=0.9\end{array}$ & 20 & 41.2847 & 21.2847 & 0.9994 \\
\hline & $\begin{array}{l}\text { 3Haar- } \\
Q=0.01\end{array}$ & -20 & 10.9299 & 30.9299 & 0.6085 \\
\hline & $\begin{array}{l}\text { 3Haar- } \\
\mathrm{Q}=0.01\end{array}$ & -10 & 20.8240 & 30.824 & 0.9367 \\
\hline & $\begin{array}{l}\text { 3Haar- } \\
Q=0.01\end{array}$ & 10 & 31.3164 & 21.3164 & 0.9936 \\
\hline & $\begin{array}{l}\text { 3Haar- } \\
Q=0.01\end{array}$ & 20 & 31.7827 & 11.7827 & 0.9943 \\
\hline
\end{tabular}

Table 10 reveals that the best value in improvement is $30.9299 \mathrm{~dB}$ at input $\mathrm{SNR}=-10 \mathrm{~dB}$ and process noise $\mathrm{Q}=0.01$ with number of decomposition levels $=7$. The best correlation coefficient is at input $\mathrm{SNR}=20 \mathrm{~dB}$ and number of decomposition levels $=7$ and process noise $\mathrm{Q}=0.9$

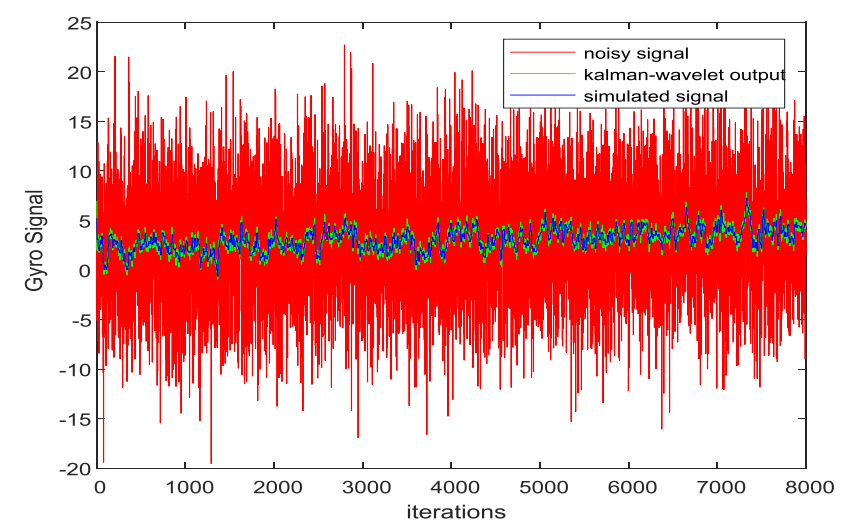

Fig 28. O/P signal for cascaded mode Kalman - Haar at $\mathrm{Q}=0.01$ and 3 levels of decomposition when input $\mathrm{SNR}=-$ $20 \mathrm{~dB}$

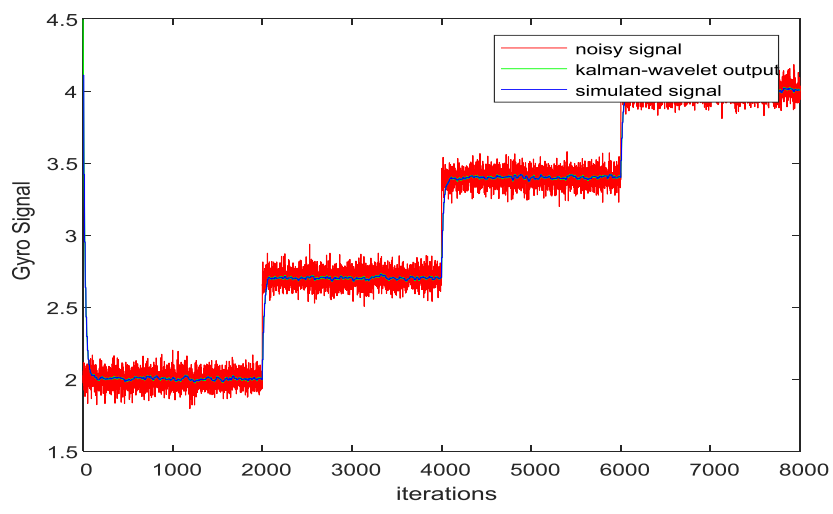

Fig 29. O/P signal for cascaded mode Kalman - Haar at $\mathrm{Q}=0.01$ and 3 levels of decomposition when input $\mathrm{SNR}=$ $20 \mathrm{~dB}$

Table 11 Cascaded Mode Kalman then 3 levels Haar wavelet output metric values

\begin{tabular}{|c|c|c|c|c|c|}
\hline Filters & Parameters & $\begin{array}{c}\text { SNR } \\
\mathrm{I} / \mathrm{P}\end{array}$ & $\begin{array}{l}\mathrm{SNR} \\
\mathrm{O} / \mathrm{P}\end{array}$ & $\begin{array}{c}\text { Improve } \\
\text { ment }\end{array}$ & $\begin{array}{l}\text { Cor-Co- } \\
\text { eff }\end{array}$ \\
\hline \multirow{8}{*}{$\begin{array}{c}\text { Kalman } \\
\text { then } \\
\text { wavelet } \\
\text { Q: } \\
\text { process } \\
\text { noise } \\
\text { parameter } \\
3 \text { Levels } \\
\text { decompos } \\
\text { ition }\end{array}$} & $\mathrm{Q}=0.9-3 \mathrm{Haar}$ & -20 & 2.2429 & 22.2429 & 0.2970 \\
\hline & $\mathrm{Q}=0.9-3 \mathrm{Haar}$ & -10 & 15.1438 & 25.1438 & 0.8215 \\
\hline & $\mathrm{Q}=0.9-3 \mathrm{Haar}$ & 10 & 34.7329 & 24.7329 & 0.9971 \\
\hline & $\mathrm{Q}=0.9-3 \mathrm{Haar}$ & 20 & 42.3766 & 22.3766 & 0.9995 \\
\hline & $\mathrm{Q}=0.01-3 \mathrm{Haar}$ & -20 & 10.8853 & 30.8853 & 0.5662 \\
\hline & $\mathrm{Q}=0.01-3 \mathrm{Haar}$ & -10 & 20.1395 & 30.1395 & 0.9227 \\
\hline & $\mathrm{Q}=0.01-3 \mathrm{Haar}$ & 10 & 29.4059 & 19.4059 & 0.9901 \\
\hline & $\mathrm{Q}=0.01-3 \mathrm{Haar}$ & 20 & 31.9414 & 11.9414 & 0.9945 \\
\hline
\end{tabular}

Table 11 reveals that the best value in improvement is $30.8853 \mathrm{~dB}$ at input $\mathrm{SNR}=-20 \mathrm{~dB}$ and process noise $\mathrm{Q}=0.01$ with number of decomposition levels $=3$ and the best correlation coefficient is at input SNR $=20 \mathrm{~dB}$ and number of decomposition levels $=3$ and process noise $\mathrm{Q}=0.9$

Figure 30 shows the highest improvement in SNR and the lowest improvement in SNR for every filter at a certain parameter and a comparison with the simulated signal in Fig 9. 


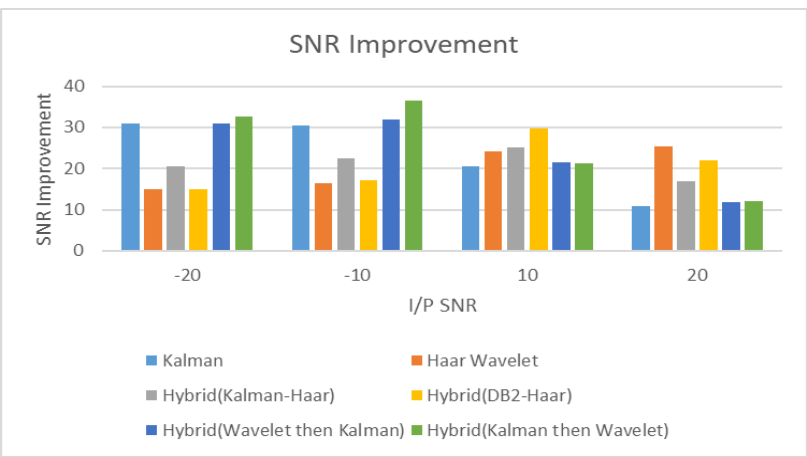

Fig 30. SNR improvement for every technique Table 12 Comparison between output metric values of different techniques at $(\mathrm{Q}=0.01$ and 7 levels of decompositions)

\begin{tabular}{|c|c|c|c|c|c|c|c|c|}
\hline Filters & \multicolumn{4}{|c|}{ SNR Improvement } & \multicolumn{4}{c|}{ Correlation Coefficient } \\
\hline SNR input & -20 & -10 & 10 & 20 & -20 & -10 & 10 & 20 \\
\hline Kalman & 30.90 & 30.36 & 20.57 & 10.89 & 0.6238 & 0.9261 & 0.9924 & 0.9930 \\
\hline Haar Wavelet & 15.037 & 16.50 & 24.12 & 25.28 & 0.1409 & 0.4408 & 0.9967 & 0.9997 \\
\hline $\begin{array}{c}\text { Hybrid(Kalman- } \\
\text { Haar) }\end{array}$ & 20.60 & 22.47 & 25.15 & 16.91 & 0.2345 & 0.7178 & 0.9974 & 0.9982 \\
\hline $\begin{array}{c}\text { Hybrid(Haar- } \\
\text { DB2) }\end{array}$ & 14.95 & 17.21 & 29.71 & 22.03 & 0.1414 & 0.4914 & 0.9991 & 0.9995 \\
\hline $\begin{array}{c}\text { Hybrid(Wavelet } \\
\text { then Kalman) }\end{array}$ & 30.93 & 31.97 & 21.61 & 11.76 & 0.6909 & 0.9489 & 0.9940 & 0.9942 \\
\hline $\begin{array}{c}\text { Hybrid(Kalman } \\
\text { then Wavelet) }\end{array}$ & 32.56 & 36.42 & 21.30 & 12.05 & 0.6998 & 0.9819 & 0.9936 & 0.9946 \\
\hline
\end{tabular}

Table 12 reveals that the best value in improvement is $36.42 \mathrm{~dB}$ at input $\mathrm{SNR}=-10$ with number of decomposition levels $=7$

\section{CONCLUSION}

An efficient technique has been proposed to decrease the noise from gyroscope signal. This technique uses hybrid methods to denoise the signal. In the first method, both Haar wavelet denoising and Kalman filtering are implemented in parallel and the results are averaged. In the second method, both Haar wavelet denoising and Daubechies wavelet denoising are implemented in parallel and the results are averaged. In the third method, both Haar wavelet denoising and Kalman filtering are implemented in cascaded mode where the output of the Kalman filtering is the input of the Haar wavelet denoising. In the fourth method, both Haar wavelet denoising and Kalman filtering are implemented in cascaded mode, where the output of the Haar wavelet denoising is the input of the Kalman filtering. Wavelet denoising depends on a thresholding strategy. On the other hand, the Kalman filtering depends on estimation theory. In the worst case of SNR, the cascaded structure comprising Kalman filtering and then Haar wavelet denoising achieved the best performance. The rationale behind this conclusion is the difference between the basic theory of the two stages. The probolistic nature of Kalman filtering estimation removes most of the noise. The remaining noise is removed during the wavelet thresholding process.

\section{REFERENCES}

[1] X. Chen, "Adaptive filtering based on the wavelet transform for FOG on the moving base," dvances in Intelligent Computing pp.447-455, 2005.
[2] B. Ralph, A, C. Lefevre, H, and J. Shaw, H, “An Overview of Fiber optic Gyroscopes,” Lightwave Technology, vol. LT-2, 1984.

[3] Hervé C. Lefèvre, Zhang Guicai, Wang Wei, "Optic fiber gyroscope," Beijing: National Defense Industry Press, 2004.

[4] H. C. Lefevre, "The fiber-optic gyroscope," Artech house, 2014.

[5] C. H. Hua, R. Zhang, and M. H. Zhang, "Filtering of long-term dependent fractal noise in fiber optic gyroscope," Journal of system Engineering and Electronics 21 pp.1041-1045, 2010.

[6] N. F. Song, C. X. Zhang, and X. Z. Du, "Analysis of vibration error in fiber optic gyroscope," Conference on Advanced Sensor Systems and Applications, SPIE Proceedings Shang Hai China 4920 pp.115$121,2002$.

[7] S. M. Bielas, "Stochastic and dynamic modeling of fiber gyros," SPIE Fiber Optic and Laser Sensors XII pp.240-254, 1994.

[8] H. Good wall, Chiang and N. El-Sheimy, "Positional Accuracy Enhancement of an Ins/gps Integrated System," Coordinates magazine, vol. 2. pp.10-16, 2001.

[9] A.R. Stubberud, X.H. Yu, "Signal processing for micro-inertial sensors," in: RTO Meeting Proceedings 44, Advances in Vehicle Systems Concepts and Integration, Neuilly-Sur-Seine, France, 2000.

[10] D.S Bayard, S.R Ploen, "High accuracy inertial sensors from inexpensive components," US patent 0187623, 2003.

[11] Chen Shufen, Zhu Yong, Qin Bingkun et al, "Theoretical analysis of noise on IFOG with integrated optics chip," Optical Technique, 29(3):8 10, 2003.

[12] Huang Zhangyong, "Photoelectronic device and component using in optical fibre communication," Beijing University Posts and Telecommunications Press, 2001.

[13] N. El-Sheimy, Naser and Noureldin, "Wavelet Based De-Noising for IMU Alignment," IEEE Aerospace and Electronic Systems Magazine, vol. 19, pp. 32- 39. 2004.

[14] Fuqiang Liu, Fanming Liu, Wenjing Wang and Bo Xu, "MEMS Gyro's Output Signal Denoising Based on Wavelet Analysis," Proceedings of the 2007 IEEE International Conference on Mechatronics and Automation, China, pp.5 - 8, August 2007.

[15] D. Donoho, "Denoising by soft thresholding," IEEE Trans. On Information Theory, Vo1.41(3). 1995.

[16] LAWRENCE “The Principles of Mechanical Gyroscopes,” 1998

[17] University of Victoria. Microelectromechanical systems, 2015.

http://www.engr.uvic.ca/_mech466/MECH466-Lecture-1.pdf(lastaccessed:January11,2016).

[18] Changjoo Kim, Woon Tahk Sung, Sangkyung Sung, Sukchang Yun, and Young Jae Lee, "On the Mode-Matched Control of MEMS Vibratory Gyroscope via Phase- Domain Analysis and Design," IEEE / ASME Transactions on Mechatronics, vol. 14, no. 4, August 2009 .

[19] Z. Guo, Z. Yang, L. Lin, Q. Zhao, J. Cui, X. Chi and G. Yan. "Decoupled comb capacitors for microelectromechanical tuningfork gyroscopes," IEEE Electron Device Letters 31(1): pp.2628,2010.

[20] S. W. Yoon, "Vibration-induced errors in MEMS tuning fork gyroscopes." Sensors and Actuators A: Physical, pp. 32-44, 2012.

[21] G. Sagnac, "L'éther lumineux démontré par l'effet du vent relatif d'éther dans un interféromètre en rotation uniforme," Compterenduz à l'Académie des Sciences, vol. 95, 1913, pp. 708-10.

[22] E. J. Post, Sagnac effect, “Rev. Modern Phys.," pp. 475-94, 1967.

[23] LAWRENCE, “A.: Modern Inertial Technology," Second Edition, Springer-Verlag New York, 1998

[24] L. Wang, Y. Hao, F. Wang, "Calibration of Low Cost MEMS Inertial Measurement Unit for an FPGA-based Navigation System," IEEE International Conference on Information and Automation, pp. 181-186, June 2011.

[25] C. Saraporn, T. Dolwichai, J. Srisertpol and K. Teeka. "Signal Conditioning of Low-cost Gyroscope Using Kalman Filter and Nonlinear Least Square Method" Advanced Materials Research, Trans Tech Publ, (2013).

[26] H. Qian, Q. Xia, et al., "On modeling of random drift of MEMS gyroscope and design of Kalman filter," International Conference on Mechatronics and Automation, pp. 4355-4360, August 2009.

[27] I. Daubechies, "Ten Lectures on Wavelets", Society for Industrial and Applied Mathematics," ISBN 0-89871-274-2, 1992. [28] http://www.ece.northwestern.edu/localapps/matlabhelp/toolbox/ wavelet/ch06 a44.html

[29] S. L. Sabat, P. Rangababu, K. Karthik, G. Krishhnaprasad and J. Nayak. "System on chip implementation of 1-D Wavelet transform based denoising of Fiber Optic Gyroscope signal on FPGA," Annual IEEE India Conference, 2011. 